\title{
ANÁLISE FÍSICO-QUIMICA COMPARATIVA DE SABONETES LÍQUIDOS
}

\section{COMPARATIVE PHYSICAL-CHEMICAL ANALYSIS OF LIQUID SOAP}

\author{
Anna Caroline LOPES ${ }^{1}$; Amanda de MORAES ${ }^{1}$; Ana Flávia Reda de OLIVEIRA ${ }^{1}$; \\ Bianca Pontes GUIMARÃES ${ }^{1}$; Camila Freitas de OLIVEIRA²; Fernando César Martins \\ BETIM²; Amanda Lyra MARTINEZ³; Vanessa Barbosa BOBEK ${ }^{3}$
}

1 - Acadêmicos do curso de Farmácia do Centro de Ensino Superior dos Campos Gerais (CESCAGE), Ponta Grossa/PR

2 - Doutorandos do programa de Ciências Farmacêuticas da Universidade Federal do Paraná UFPR.

3 - Professoras do departamento de Farmácia, Curso de Farmácia - Centro de Ensino Superior dos Campos Gerais (CESCAGE).

Autor para correspondência: anna.kfc19@gmail.com

\section{RESUMO:}

O presente trabalho teve como objetivo realizar testes físico-químicos em duas amostras de sabonete líquido diferentes, a fim de compará-las. As análises foram realizadas no laboratório de química do Centro de Ensino Superior dos Campos Gerais (CESCAGE) e no laboratório de produção de medicamentos (LAPMED) da Universidade Estadual de Ponta Grossa (UEPG). Os parâmetros físico-químicos analisados foram: densidade através do método da picnometria, viscosidade pelo método do viscosímetro rotacional (Brookfield) e verificação do $\mathrm{pH}$ com o auxílio de um peagâmetro digital. As análises das amostras $\mathrm{A}$ e $\mathrm{B}$ foram realizadas em triplicatas e os resultados obtidos foram comparados com a literatura. Os valores de densidade encontrados foram $1,003 \mathrm{~g} / \mathrm{cm} 3$ para a amostra A e 0,6207 g/cm3 para a amostra B. Os valores de $\mathrm{pH}$ e viscosidade encontrados foram, respectivamente 5,76, 6RPM/s 10,69Pa.s, 12RPM/s 8,28Pa.s para a amostra A, e 6,56, 6RPM/s 4,68Pa.s, $12 R P M / s 3,59 P a$.s para a amostra $B$. Com a realização às análises físico-químicas pode ser observado uma diferença significativa entre as amostras, sendo a amostra A mais densa, mais viscosa e com o pH mais ácido que a amostra B.

Palavras-chave: sabonete líquido; descontaminação; parâmetros físico-químicos.

\section{ABSTRACT:}

The objective of the present work was to perform physical-chemical tests of two different liquid soap samples in order to compare them. The analyzes were carried out in the chemistry laboratory of Faculdades Ponta Grossa (FacPG) and in the laboratory of production of medicines (LAPMED) of Ponta Grossa State University (UEPG). The physicalchemical parameters analyzed were: density through the method of picnometry, viscosity by the rotational viscosimeter method (Brookfield) and verification of the $\mathrm{pH}$ with the aid of a digital $\mathrm{pH}$ meter. The analyzes of samples $\mathrm{A}$ and $\mathrm{B}$ were performed in triplicates and the results obtained were compared with the literature. The values of density found were 1.003 $\mathrm{g} / \mathrm{cm} 3$ for sample A and $0.6207 \mathrm{~g} / \mathrm{cm} 3$ for sample B. The values of $\mathrm{pH}$ and viscosity found were respectively 5.76, 6RPM / s 10.69Pa.s, 12RPM / s 8.28Pa.s for sample A, and 6.56, 6RPM / s 4.68Pa.s, 12RPM / s 3.59Pa.s for sample B. With the accomplishment of the physico-chemical analyzes a significant difference between the samples can be observed, being the sample A more dense, more viscous and with the $\mathrm{pH}$ more acid than the sample $\mathrm{B}$. Keywords: liquid soap; decontamination; physical-chemical parameters. 


\section{INTRODUÇÃO}

Os sabonetes líquidos foram lançados no mercado na década de 70 e rapidamente alcançaram o sucesso, pois suas formulações apresentavam um pH próximo ao da pele, fato que nunca havia sido observado antes em sabonetes tradicionais, já que estes são alcalinos por natureza. Outra característica dos sabonetes líquidos que contribuiu para o seu sucesso foi o tipo de embalagem, a qual permite a utilização do produto com o mínimo de contato com o ambiente externo (MORGANTI, 1995; LUNDMARK, 2008).

Os sabonetes líquidos utilizados para descontaminação, geralmente comercializados em farmácias ou supermercados, agem na limpeza superficial da derme. Para que isso ocorra sem agredir a pele é necessário que estes apresentem propriedades físico-químicas específicas, e sejam acrescidos de agentes hidratantes, como a glicerina, que evita o ressecamento (HIGIOKA, 2013).

O pH é um dos principais mecanismos de proteção da pele, devendo-se à produção de ácido láctico e conferindo à superfície cutânea aquilo que se convencionou designar por "manto ácido cutâneo", e é constantemente desafiado por agressores externos como a poluição, mudanças de temperatura e os produtos químicos. Ele varia de acordo com ambos os gêneros e onde está situado no corpo (EUCERIN, 2016).

$\mathrm{O}$ pH da pele é levemente acidificado $(4,6$ - 5,8), o que contribui para que ocorra a proteção fungicida e bactericida em sua superfície. Observa-se também, uma importante propriedade das secreções cutâneas em apresentar capacidade tamponante (LEONARDI et al, 2002).

Algumas regiões do corpo tem seu termômetro de saúde definido principalmente pelo índice de potencial hidrogeniônico, como é o caso da região íntima da mulher. O pH da vagina saudável é ácido, com valores que oscilam entre 3,8 a 4,2, pois estas são as condições ideais de sobrevivência dos microrganismos que compõem a flora microbiana do ambiente vaginal saudável (BRUSCO,2009; DI LAROUFFE, 2009).

A redução do nível desses microrganismos é a principal causa de infecções e irritações, e para que esse índice seja mantido é necessário que os produtos químicos utilizados nessa região estejam de acordo com o que o corpo necessita. (ANVISA, 2008).

Neste sentido, com o intuito de saber se o cuidado com a saúde do consumidor é respeitado, objetivou-se neste trabalho analisar amostras de dois tipos de sabonete líquido sendo um para a região íntima e outro comum através de testes físico- químicos os quais contribuem para o controle da qualidade do produto. 


\section{MATERIAL E MÉTODOS}

Foram analisados os seguintes parâmetros físico-químicos nas duas amostras de sabonete líquido (sabonete íntimo e sabonete comum), de acordo com o Guia de Estabilidade de produtos cosméticos sugerido pela Agência Nacional de Vigilância Sanitária (BRASIL, 2004): densidade, $\mathrm{pH}$ e viscosidade.

\subsection{Densidade}

O procedimento consistiu na utilização do picnômetro limpo e seco, com capacidade de $50 \mathrm{~mL}$, previamente calibrado. Pesou-se o picnômetro vazio, com a água e em seguida com a amostra e os valores foram anotados, assim como a temperatura que se encontravam as amostras. A densidade relativa foi calculada pelo coeficiente entre a massa da amostra líquida e a massa da água, ambas a 25ํㅡ (BRASIL, 2010).

\section{$2.2 \mathrm{pH}$}

A medida do $\mathrm{pH}$ foi realizada através do método potenciométrico, utilizando peagâmetro digital (Gehaka PG 2000 São Paulo-Brasil), previamente calibrado com as soluções tampões ph 4,0 e 7,0. Preparou-se uma solução a 10\%, usando-se água destilada como solvente e procedeu-se a medida do $\mathrm{pH}$ em triplicata para cada amostra.

\subsection{Viscosidade}

A viscosidade aparente foi determinada utilizando-se viscosímetro de Brookfield (QuimisQ860MDiadema/São Paulo-Brasil). Em ambas as amostras o spindle utilizado foi o número 3. Para parâmetro de comparação, foram utilizadas velocidades de $6 \mathrm{RPM} / \mathrm{s}$ e 12RPM/s, sendo os resultados expressos em Pa.s, realizados em triplicata.

\section{RESULTADOS E DISCUSSÃO}

Foram avaliadas duas amostras de sabonete líquido comerciais, sendo uma delas sabonete líquido íntimo para a região intima feminina e outra de sabonete líquido comum. Os resultados estão descritos na Tabela 1 . 
Tabela 1 - Resultado das análises físico-químicas das amostras de sabonete líquido comerciais

\begin{tabular}{ccc}
\hline AMOSTRA & A - íntimo & B - normal \\
\hline DENSIDADE (média \pm DP) & $1,0030 \mathrm{~g} / \mathrm{cm}^{3}$ & $0,6207 \mathrm{~g} / \mathrm{cm}^{3}$ \\
pH( média \pm DP) & $5,76 \pm 0,11$ & $6,56 \pm 0,05$ \\
& $6 R P M / \mathrm{s} 10,69 \mathrm{~Pa} / \mathrm{s} \pm 0,25$ & $6 \mathrm{RPM} / \mathrm{s} \quad 4,68 \mathrm{~Pa} / \mathrm{s} \pm 0,13$ \\
VISCOSIDADE (média \pm DP) & $12 \mathrm{RPM} / \mathrm{s} 8,28 \mathrm{~Pa} / \mathrm{s} \pm 0,19$ & $12 \mathrm{RPM} / \mathrm{s} 3,59 \mathrm{~Pa} / \mathrm{s} \pm 0,08$ \\
\hline
\end{tabular}

A densidade é representada pela relação entre a massa de uma substância e o volume que ela ocupa. De acordo com a Farmacopeia Brasileira (BRASIL, 2010), no caso de líquidos ou semi-sólidos esta característica pode sugerir a incorporação de ar ou a perda de ingredientes voláteis e água.

Foi observada uma diferença de valores de densidade das duas amostras. A amostra $B$ apresentou uma densidade menor do que a amostra $A$ o que pode ser indicativo de perda de compostos voláteis. Não foi encontrado na literatura um valor padrão de densidade para sabonetes líquidos. No entanto, o valor mais comum encontrado foi 1,003 $\mathrm{g} / \mathrm{cm}^{3}$ (FERREIRA, 2010).

Conforme reportado na literatura (LEONARDI et al., 2002), a pele não possui pH neutro, e o pH varia conforme a região do corpo ou da idade, no entanto, de maneira geral, o chamado pH fisiológico da pele é entre $(4,5$ - 6,0), onde o mesmo executa a proteção bactericida e fungicida em sua superfície. Neste sentido, pode ser verificado que as duas amostras revelaram valores de $\mathrm{pH}$ fora dos valores ideais. A análise do $\mathrm{pH}$ da formulação é de extrema importância, uma vez que o $\mathrm{pH}$ do produto deve ser mantido durante todo o seu prazo de validade, pois a alteração do $\mathrm{pH}$ pode significar alteração da estabilidade da formulação (LEONARDI; MAIA CAMPOS, 2001).

A viscosidade pode ser explicada de forma simples como "dificuldade ao escoamento", ou seja, é a medida de resistência do sistema em fluir quando submetida a uma força. Desta forma, quanto maior a viscosidade de um produto, maior será essa resistência, podendo interferir ainda na capacidade de espalhamento do produto sobre uma superfície (LAHOUD; CAMPOS, 2010).

A viscosidade é uma característica relevante no desenvolvimento de produtos 
cosméticos e está totalmente relacionada à aceitação do consumidor (CHORILLI et al., 2006).

Utilizou-se o viscosímetro de Brookfield para análise do perfil da viscosidade e padronizaram-se as leituras utlizando o spindle 3 e velocidades de rotação de 6 e 12 rpm (SILVEIRA, 2007). As duas amostras apresentaram valores de viscosidade diferentes, sendo a amostra A mais viscosa que a amostra $B$.

Constatou-se ainda, que os resultados de $\mathrm{pH}$ obtidos da amostra $\mathrm{A}$ diferem dos valores da embalagem da mesma, que afirmam que o $\mathrm{pH}$ ideal estaria entre 4,5 e 5,5.

\section{CONCLUSÃO}

A partir da comparação dos parâmetros físico-químicos analisados como densidade, viscosidade e $\mathrm{pH}$ das amostras de sabonete líquido normal e sabonete íntimo comparadas, foi possível identificar divergências nas informações contidas no rótulo da embalagem, especificamente para o pH obtido na análise de uma das amostras. Logo, conclui-se que os consumidores não estão adquirindo realmente o produto pelo qual estão pagando.

\section{REFERÊNCIAS}

ANVISA. Higienização das mãos em serviços de saúde. Disponível em: < http://www.anvisa.gov.br/hotsite/higienizacao_maos/manual_integra.pdf> Acesso em: $15 / 08 / 2016$

BRASIL. Ministério da Saúde. Anvisa.Guia de estabilidade de produtos cosméticos. 1. ed., v. 3, Brasília: ANVISA,2004.

BRASIL, Ministério da Saúde. Anvisa.Farmacopeia Brasileira.1ํㅡ. Ed. v, Brasília: ANVISA.2010. BRUSCO, A.G. Sabonete líquido especial para higiene genital e restauração do $\mathrm{pH}$ da pele e mucosa. Disponível em: <http://www.oligoterapia.com.br> Acesso em: 20/08/2016

CHORILLI, M.; UDO, M.S.; CAVALLINI, M.E. \& LEONARDI, G.R. Desenvolvimento e estudos preliminares de estabilidade de formulações fotoprotetoras contendo Granlux GAI- 
45 TS. Revista de Ciências Farmacêuticas Básica e Aplicada. 2006; 27: 237-246.

EUCERIN Manto ácido cutâneo. Disponível em: <https://www.eucerin.pt/sobre-apele/conhecimentos- basicos-da-pele/skins-ph> Acesso em: 19/08/2016

FERREIRA, AO. Guia Prático da Farmácia Magistral. 4ํㅗㄹ ed. São Paulo: Pharmabooks; 2010.

HIGIOKA, A.S. Desenvolvimento e controle físico-químico de sabonete líquido com digluconato de clorexidina. Revista de Ciências Farmacêuticas Básica e Aplicada, Vol. 34, No 4 (2013).

LAHOUD, M.H; CAMPOS, R. Aspectos teóricos relacionados à reologia farmacêutica. Visão Acadêmica, Curitiba, n.1, Jun./2010

LEONARDI, G.R. Influência do ácido glicólico na penetração cutânea da vitamina A palmitato e na estabilidade física de formulações dermocosméticas. 1997. 114p. Dissertação (Mestrado). Faculdade de Ciências Farmacêuticas de Ribeirão Preto, Universidade de São Paulo, Ribeirão Preto, 1997.

LEONARDI, G.R.; MAIA CAMPOS, P.M.B.G. Estabilidades de formulações cosméticas. Int. J. Pharm. Compound. 2001; 3(4): 154-156.

LEONARDI, G.R.; GASPAR, L.R; CAMPOS, P. M.B.G.M. Estudo da variação do pH da pele humana exposta à formulação cosmética acrescida ou não das vitaminas a, e ou de ceramida, por metodologia não invasiva. Anais Brasileiros de Dermatologia. Rio de janeiro, v. 77, n.5, p. 563-569, 2002.

LUNDMARK, L. The evolution of liquid soap. Cosmetics \& Toiletries, v.1 07, p. 49-53, 2008. MORGANTI, P. Natural soap and syndet bars. Cosmetic. Toilet., v. 110, p. 89-97, 1995.

SILVEIRA, C. A.S. Uso do viscosímetro de Brookfield em determinações reológicas. Polímeros: Ciência e tecnologia. p.41-43, 1991. 